\title{
Meta-Responsibility in Corporate Research and Innovation: A Bioeconomic Case Study
}

\author{
Matti Sonck ${ }^{1,2, *,+}$, Lotte Asveld ${ }^{1}(\mathbb{D})$ and Patricia Osseweijer ${ }^{1}$ \\ 1 Department of Biotechnology, Faculty of Applied Sciences, TU Delft, 2629 HZ Delft, The Netherlands; \\ L.Asveld@tudelft.nl (L.A.); P.Osseweijer@tudelft.nl (P.O.) \\ 2 Fortum Power and Heat Oy, Keilalahdentie 2-4, FI-00048 Fortum, Espoo, Finland \\ * Correspondence: M.M.Sonck@tudelft.nl \\ + This research article represents the views of individual members only and should not be taken as a statement \\ of the views of the organisation as whole.
}

Received: 29 October 2019; Accepted: 17 December 2019; Published: 19 December 2019

check for updates

\begin{abstract}
The term "responsibility" embodies many meanings, also in the context of corporate research and innovation (R\&I). The approach of Responsible Research and Innovation (RRI) has emerged as a promoter for responsible conduct of innovation but so far lacks a systematic framework for describing, inventorying, and eventually managing different responsibilities that R\&I units hold in companies and further in society. In this paper we take forward the idea of developing RRI into a "meta-responsibility" approach, for orchestrating responsibilities in corporate R\&I. First, we introduce a frame for defining responsibility, which is inclusive of four elements (care, liability, accountability, and responsiveness), and is attentive to the intrinsic uncertainty of the R\&I setting. Drawing on empirical data from interviews, we then examine how these responsibility elements become operationalised in an actual R\&I project. As a result, we develop a meta-responsibility map for corporate R\&I, bringing various and sometimes contradicting principles, expectations and obligations under the common terminology of responsibility. We suggest that such integrative outlook on responsibilities increases theoretical solidity and practical applicability of RRI as an innovation management approach. Regarding R\&I practices, we conclude that the meta-responsibility map can support R\&I units in exploring their co-existing and sometimes conflicting responsibilities, and in managing those responsibilities in the highly uncertain R\&I setting. In particular, meta-responsibility shows applicability in (i) balancing risk and precaution, (ii) exposing and addressing concerns about the goals and impacts of innovation, and (iii) accelerating sectoral transition whilst securing one's own competitive advantage in it.
\end{abstract}

Keywords: innovation management; responsible research and innovation; RRI; industry; bioeconomy; biorefineries

\section{Introduction}

Companies, like all institutions, wield various responsibilities in society. In addition to economic obligations to shareowners and legal compliances, during the past decades, companies have assumed social and morally binding responsibilities beyond what is legally required of them [1]. With the escalation of global problems such as climate change and food insecurity, companies are increasingly seen to hold a key position in finding and developing solutions for societal challenges [2]. Considering this co-existence of different scopes and understandings of what corporate responsibility entails, any demand for introducing new responsibilities needs to be framed clearly with pre-existing responsibilities taken into account. 
In recent years, a new call for responsibility has been added to those already existing, focusing on research and innovation (R\&I) as a specific and relevant part of corporate activities. The literature of Responsible Research and Innovation (RRI, or RI) sets out to promote a wider responsibility in the context of R\&I management and activities, with the aim of enhancing the "societal embeddedness" of innovations. According to RRI's dominant idea, by Owen et al. [3], R\&I should anticipate and reflect on the impacts of an innovation in society, and innovators should be responsive by adjusting the shape (e.g., design) and direction of the innovation according to these considerations. This is a reasonable call, firstly considering that R\&I units and teams play a key role in implementing the strategic goals of what a company aspires to be in the future-and thus how the company will impact the surrounding society and natural environment. Secondly, R\&I is on the frontlines in observing and tackling uncertainties and unexpected turns that inherently accompany future-oriented activities.

Many activities endorsed in RRI are already mainstream in companies-such as stakeholder dialogue and risk assessments-and their value for successful innovation is widely acknowledged [2]. However, RRI as an integral, systematic approach remains unfamiliar (and unimplemented) in corporate R\&I. As remarked by van de Poel and Sand [4], implementing RRI would attribute a range of new responsibilities into the daily work routine of R\&I teams. As with any new approach, alleged benefits are carefully weighed against the workload added to existing duties and obligations. To convincingly communicate its added value and to spark any institutional change, the approach of Responsible Research and Innovation needs to be very specific in terms of what kind of responsibility it exactly demands from R\&I managers and personnel and how novel responsibilities align with existing ones.

In a similar vein, a few studies remark that RRI's practical relevance remains fundamentally hampered as long as it remains unspecific about the core concept of responsibility [5-7]. This largely boils down to the absence of a systematic framework that would provide an inventory of different responsibilities within R\&I. For instance, while RRI is portrayed as a promoter of "wider" societal and moral responsibility, no framework exists that would translate this demand into a common language with R\&I's extant responsibilities: economic, legal, contractual, as well as moral. Shortcutting without duly considering existing responsibilities is not only unsuccessful but also potentially detrimental when resulting in unclear role setting and dissolved responsibility $[1,8]$.

In response, it has been proposed that RRI should be developed into a meta-responsibility approach, providing a systematic mapping of both existing and novel responsibilities that R\&I functions hold in society [7,9-11]. This airplane view can reveal gaps, dependencies, and conflicts among current and emerging demands and expectations faced by corporate R\&I. Furthermore, meta-responsibility would provide a foundation for introducing and aligning novel responsibilities, e.g., for meeting particular societal goals and for formulating practical recommendations for R\&I personnel for their implementation [7].

Taking forward this approach, the paper at hand develops a model for meta-responsibility and demonstrates its applicability in practical R\&I. By means of case study, we systematically explore responsibilities in a corporate R\&I project, with the following research question: How do (theoretically formulated) elements of responsibility become operationalised in practical R\&I, and how can this outlook support responsible innovation? For theoretical basis, Section 2 introduces the framework by Pellizzoni [12] outlining the four elements responsibility: care, liability, accountability, and responsiveness, and further, suggests an adaptation to this framework in order to render it more attentive to R\&I as a highly uncertain future-oriented setting. Section 3 presents the empirical research material and methods, featuring a corporate R\&I project in the bioeconomic sector (i.e., a manufacturing industry utilising bio-based raw materials). Bringing together theory and practice, Section 4 presents a meta-responsibility map and discusses its relevance for facilitating responsible innovation in corporate R\&I. Finally, the conclusions and limitations of the study are presented in Section 5. 


\section{Theoretical Approach: Unfolding Responsibility in Research and Innovation}

The present paper builds on an assembly of RRI studies calling for a more explicit and systematic account of the term responsibility, to support responsible innovation. As a point of departure, we look to the work of Stahl [10] proposing that RRI, in itself, should become such a framework. This implies that RRI should be reconceptualised into a meta-responsibility, to "shape, maintain, develop, coordinate and align existing and novel research and innovation-related processes, actors and responsibilities with a view to ensuring desirable and acceptable research outcomes" [10] (p. 708). Chatfield and colleagues [9] were the first to suggest utilising meta-responsibility in the private sector context as a means to enable RRI, since "fundamentally, for RRI to be adopted in industry, it must be implementable within existing organisations and aligned with their existing processes, codes and responsibilities" (p. 17).

Timmermans et al. [7] were the first to apply meta-responsibility for inventorying responsibilities in an industrial R\&I case study. The authors modelled networks of allocated responsibilities in two industrial R\&I cases, between subjects (i.e., those who are responsible), objects (what the subjects are responsible for), norms (criteria to act responsibly), and authorities (overseeing responsibilities and attributing sanctions). The study surfaced multiple responsibility relationships between these entities, among which certain aspects of RRI were also identifiable, such as anticipation and stakeholder engagement. The authors voiced a need to develop further methodologies for mapping responsibilities, and to explore these in light of R\&I practices across different industries and types of organisation. Another mode of applying meta-responsibility is provided by Stahl et al. [11], as a "bird's eye view" to assess the extent to which RRI's principles are realised in the purposes (i.e., motivations), processes (activities undertaken), and products (outcomes) of R\&I. The authors propose a five-stage RRI maturity model for organisations and demonstrate its validity with empirical insights from three industrial R\&I cases.

Adding to the above literature, we remark that in order to devise meta-responsibility in innovation projects, one needs to define responsibility in a way that is attentive to the particularities of the R\&I context: namely, the persistent uncertainty that characterises innovation as a future-oriented activity. Here, we take as a point of reference the work by van de Poel and Sand on attributing responsibilities to innovators [4] and by Pellé and Reber on moral responsibilities in supply chains and innovation networks [6]. These RRI studies, although not referencing meta-responsibility by name, inventory different meanings of responsibility in R\&I contexts, and in this sense implement meta-responsibility. In particular, both studies broach the question of how to conceptualise and eventually undertake responsibility during an R\&I process, given the uncertainty about its outcomes and impacts.

\section{Defining Responsibility in an REI Setting}

As a framework for defining responsibility, this paper applies the account by Pellizzoni [12], who in the context of environmental governance itemised the concept of responsibility into four elements-care, liability, accountability, and responsiveness. This framework was originally introduced into RRI by Owen et al. [3] already in 2013, but has remained limitedly applied, apart from the notable adoption of responsiveness as one of RRI's key elements. A more systematic revisit of Pellizzoni's framework serves as a basis for meta-responsibility that is not far-fetched from RRI's origins.

Building on an extensive tradition of philosophical literature on responsibility, Pellizzoni [12] conceptualised the responsibility elements on the basis of two facets: justification (i.e., how an actor reasons his or her behaviour), and imputation (the possibility of tracing an action back to its agent as the causal factor). These facets are visualised as the axes in Figure 1. 


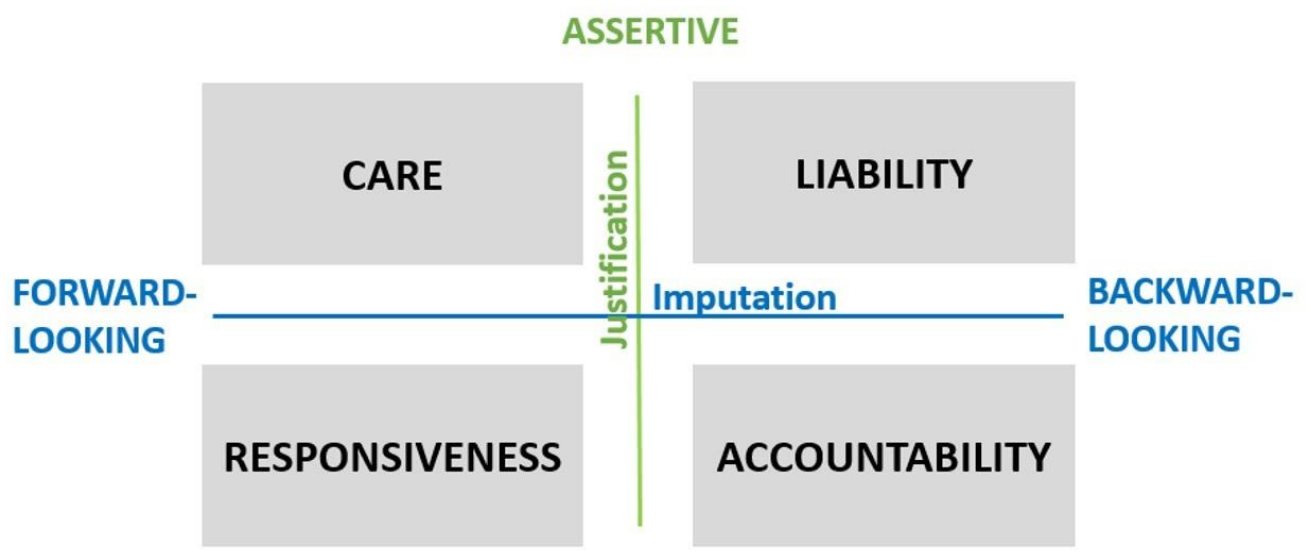

RECEPTIVE

Figure 1. A framework presenting the elements of responsibility, modified into the R\&I context based on Pellizzoni [12].

To render the framework more descriptive of the R\&I context, we elaborate the facets of justification and imputation in a somewhat different fashion than Pellizzoni. Regarding justification, we take as a point of departure the challenge of how to justify acts in light of the high uncertainty that inherently characterises R\&I projects. As future-oriented activity, not only is the outcome of an R\&I project unclear, but also its impacts on the social and natural environment are difficult to predict due to complex cause-consequence relations [4,6]. Moreover, the very the meaning of a "good outcome" can shift, e.g., with changes in consumer demands or societal values [1]. To pinpoint how this uncertainty can be addressed in R\&I, we apply the following dichotomy:

- In assertive justification, it is known what is right or wrong (or it is believed to be known).

- In receptive justification, it is less clear what is right or wrong (and there is awareness of this uncertainty).

Imputation is a close synonym for "allegation" and refers to the event of tracing an action back to its originator. With this regard, Pellizzoni makes a distinction between forward- and backward-looking responsibility, and this dichotomy has been further evoked by Pellé and Reber [6] and van de Poel and Sand [4] in the context of inventorying responsibilities in R\&I. On the one hand, R\&I essentially fosters the opportunity to "transform the future" towards what is deemed right and desirable. In line with van de Poel and Sand [4], such actions are driven by a forward-looking attitude of improving current conditions based more on virtue and "collective stewardship" and less on concerns about finger-pointing if the act turns out to be unsuccessful. On the other hand, as innovation involves risks and unexpected twists, actions can also be driven by a backward-looking safeguarding that no harm will be done. This mindset is accompanied by an expectation that acts will eventually be evaluated, with attribution of blame, punishment (or praise) to the agent [4]. In synthesis:

- forward-looking mindset is driven by a prospective aspiration to improve the current state of affairs (and if failing, trying better the next time).

- backward-looking mindset is driven by (the expectation of) retrospective evaluation on the possible harm (or benefit) caused by the action.

From this systematics, a set of four understandings for responsibility unfolds as illustrated in Figure 1. In the particular context of R\&I, we attribute the following definitions to these elements:

- Care, as the assertive, forward-looking element of responsibility. Care-motivated actions are characterised by already knowing what a good and desirable outcome is (i.e., assertiveness), and working for improving the current state of affairs to reach this outcome (forward-looking). 
- Liability, as the assertive, backward-looking element of responsibility. Liability-motivated actions focus on seeking compliance with society's set rules that are known and applied during the act (assertiveness), and avoidance harms and risks (backward-looking).

- Accountability, as the receptive, backward-looking element of responsibility. Accountabilitymotivated actions involve contemplation of what would be the right thing to do according to one's best knowledge at a given time (receptiveness) and are characterised by keen focus on the expected impacts of these actions (backward-looking).

- Responsiveness, as the receptive, forward-looking element of responsibility. Responsivenessmotivated actions involve reflection on what is right and desirable (receptiveness), while simultaneously improving the status quo (forward-looking) in the form of trying and learning. Responsive activity is open-ended in the sense that the shape and direction of the outcome is constantly being reassessed.

To lend concreteness to the abstract notions, Table 1 elaborates on each element of responsibility. The first set of examples is provided by Pellizzoni [12], while in the second set, we hypothesize examples in the private sector context. While Pellizzoni typically explicates through negation (what is not responsible), our hypothesized examples also introduce positive interpretations (what is responsible).

Table 1. Elements of responsibility elaborated.

\begin{tabular}{|c|c|c|c|}
\hline $\begin{array}{c}\text { Element of } \\
\text { Responsibility }\end{array}$ & Characterised by & Elaborations by Pellizzoni [12] & $\begin{array}{l}\text { Hypothesised Elaborations in } \\
\text { the Private Sector Context }\end{array}$ \\
\hline Care & $\begin{array}{l}\text { Knowing what is a good } \\
\text { outcome (assertive), and } \\
\text { working to advance the } \\
\text { current situation toward } \\
\text { it (forward-looking). }\end{array}$ & $\begin{array}{l}\text { The parents take care that their } \\
\text { child gets enough food. (It is } \\
\text { known that children need food, } \\
\text { and parents are supposed to } \\
\text { take care of their children). }\end{array}$ & $\begin{array}{l}\text { A company cuts carbon dioxide } \\
\text { emissions as part of its } \\
\text { sustainability strategy, so as to } \\
\text { assume care of future } \\
\text { generations. }\end{array}$ \\
\hline Liability & $\begin{array}{l}\text { Compliance with } \\
\text { society's set and known } \\
\text { rules (assertive), } \\
\text { avoidance of harms and } \\
\text { risks } \\
\text { (backward-looking). }\end{array}$ & $\begin{array}{l}\text { The parents are deemed liable in } \\
\text { court for their child's } \\
\text { malnutrition. (it could be } \\
\text { proven that the parents' neglect } \\
\text { had led to the malnutrition.) }\end{array}$ & $\begin{array}{l}\text { A company is judged to be liable } \\
\text { for the financial losses of } \\
\text { another company due to a } \\
\text { patent violation. }\end{array}$ \\
\hline Accountability & $\begin{array}{l}\text { Weighing what is the } \\
\text { right way to proceed } \\
\text { (receptive), driven by } \\
\text { contemplation of the } \\
\text { impacts of the actions } \\
\text { (backward-looking). }\end{array}$ & $\begin{array}{l}\text { The parents put the child in a } \\
\text { good but expensive school. To } \\
\text { pay for this, the parents need to } \\
\text { work long hours, and the child } \\
\text { becomes lonely and depressed. } \\
\text { Can the parents be held } \\
\text { accountable; Were they } \\
\text { supposed to know the impacts } \\
\text { of their choice and be able to } \\
\text { choose correctly? }\end{array}$ & $\begin{array}{l}\text { A Chief Executive Officer (CEO) } \\
\text { is accountable for a company's } \\
\text { shareholders, through the Board, } \\
\text { for recent financial results. (In a } \\
\text { CEO position (s)he is supposed } \\
\text { to know how to make sound } \\
\text { decisions.) }\end{array}$ \\
\hline Responsiveness & $\begin{array}{l}\text { Reflection on what is } \\
\text { right and desirable } \\
\text { (receptive), by "trying } \\
\text { and learning' } \\
\text { simultaneously with } \\
\text { improving the status quo } \\
\text { (forward-looking). }\end{array}$ & $\begin{array}{l}\text { The parents strongly oppose the } \\
\text { child's desire to become an artist. } \\
\text { The child chooses another career } \\
\text { and becomes unhappy. The } \\
\text { parents were not responsive to } \\
\text { the child's emerging aspirations, } \\
\text { and in this sense are responsible } \\
\text { for their child's condition. }\end{array}$ & $\begin{array}{l}\text { An R\&I team is responsive to the } \\
\text { expected impacts of their future } \\
\text { product on society. The team } \\
\text { consults stakeholders with help } \\
\text { of a product prototype, which is } \\
\text { then further designed to better } \\
\text { fulfil the identified needs. }\end{array}$ \\
\hline
\end{tabular}

To explore how the elements of responsibility become manifest in corporate R\&I settings, Section 3 presents the settings and design of a case study that was conducted for inventorying responsibilities in an ongoing R\&I project.

\section{Methodology: Mapping Responsibilities in a Case Study}

The case project, named Bio2X, is an R\&I project within the company Fortum-a large-size enterprise headquartered in Finland. Bio2X was chosen as the case project of this study for reasons of 
accessibility (the main author working in the case project), and its relatively early stage (implying high uncertainty, relevant to the scope of this study).

Bio2X is developing a biorefinery concept to convert lignocellulosic biomasses, such as wood and agricultural straw residues, into their structural components (i.e., fractions) by employing conversion technologies called fractionation technologies. The fractions-cellulose, hemicellulose, and lignin - would then be further manufactured into various bio-based products, in commercial partnerships with industrial manufacturers and consumer brand owners.

At the time of the study, the main milestone ahead for Bio2X was to prepare an investment proposal for building a pilot-scale biorefinery plant. In the so-called "upstream" part of the project, the Bio2X team was working with upscaling the fractionation technologies towards the pilot scale in order to get sufficient proof of technical feasibility for the investment proposal. On the "downstream" side, the aim was to establish demand for Bio2X's fractions among manufacturing industries. The team members were engaged in networking with companies, e.g., in the textile, construction, and cosmetics industries, that were testing the use of Bio2X's fractions in manufacturing industrial and consumer applications.

For supplementary background, we highlight features of Bio2X that frequently appeared as characterising the team's work.

At the time of this case study, Bio2X was a relatively early-phase project, termed as the "pre-engineering phase" by the team members. In terms of a typical innovation process model [5], the project, to a major extent, was in the exploration stage (applied research) and to some extent in the development stage (pilot and demonstration), with the implementation stage (delivering value to consumers and society) still years ahead. Characteristic of early-phase R\&I is high uncertainty regarding the project's outcome $[1,13]$. In the Bio2X case, there were multiple open product and technology options, as well as uncertainty as to what extent the fractions produced on a small scale were representative of large production scales. In the company's R\&I structure, the project was at the stage of becoming an "internal start-up", denoting a further uncertainty about the project's continuation, to some extent similar to external start-ups [14]. The Bio2X's managers devoted a considerable share of their time to "selling" the project within the company, ensuring Bio2X a role in the corporate business strategy, and attaining continued funding for the project. For instance, at the time of the interviews, Bio2X members in managerial positions were involved in corporate strategic discussions, as the company was updating its growth strategy.

Another characteristic of Bio2X was its highly collaborative working model. Bio2X did not possess research facilities of its own, instead experiments and scale-ups were conducted at the collaborators' premises. The fractionation technology developers were start-up enterprises, financially supported by the company to enable technology scale-up and working closely with the Bio2X team members. Moreover, the business models envisioned for the full-scale biorefinery were based on the physical co-existence of several industrial partners adjacent to the biorefinery, for further manufacturing the fractions into end products (i.e., an industrial ecosystem). A high degree of novelty is a known driver for collaborative ways of working [15]. In general, the bio-based manufacturing sector is still largely an emerging one. In Bio2X case in particular, bio-based manufacturing was largely a novel territory for the company, which was undergoing strategic renewal to expand beyond its current business area of energy generation. Team members expressed the view that Fortum and Bio2X were "accelerators" of the emerging bio-based industrial sector: Being a large enterprise coming from outside the established manufacturing sector, there are both resources and motivation to upscale novel biorefining technologies for debottlenecking industrially relevant scales of bio-based materials for the final product manufacturers.

\section{Materials and Methods}

Data was gathered from 13 semi-structured interviews of approximately 90 minutes each, conducted over a period of 4 months in 2018. The semi-structured protocol was chosen in light of the exploratory nature of the study, as it permits the respondents "to talk about what the respondent 
wants to talk about, so long as it is anywhere near the topic" [16] (pp. 48-49). The questions were grouped into five sets (see Appendix A). In the first set of questions, the interviewees were asked to describe the project and their tasks in it, what particularly motivated them in the project, and what their main concerns relating to the project and its outcome were. The next question set explored how the respondents understood "corporate responsibility", how Bio2X links to corporate responsibility, and what "societal and environmental impacts" the respondents envision would result from the project-both positive and negative. In the third set, the respondents were asked to describe the current stage of the project, and how it is like to make decisions at this stage. The fourth set explored how and to what extent societal and environmental impacts had been taken into consideration and eventually into decision-making. Finally, the interviewees were asked about the stakeholders and ways of working with them. The questions were ordered in a sequence allowing a good "flow" (easy transition from topic to topic) as well as free association before serving more specific (and in that sense steering) questions.

There were 13 interviewees in total, comprising of 7 team members (project managers, technology experts, trainees), 4 external consultants working for the project ( 3 with business and marketing background and 1 with academic background), and 2 "internal stakeholders" from other units of the company ( 1 sustainability expert and 1 from upper management). The interviewees were chosen and contacted by the main author who was also the interviewer. Regarding the sampling method, all the team members working in Bio2X at the time of the study were chosen as interviewees (save the interviewer). With the external experts and internal stakeholders, the purposive sampling method [16] was followed: firstly, to gain a more diverse outlook on the project by increasing the number of interviewees, and secondly, by bringing in insights from their particular fields of expertise.

The interviews were recorded, and the recordings were translated and transcribed into English. For qualitative analysis, the transcripts were coded and sorted using the MAXQDA coding tool. The coded text fragments across different transcripts were then harvested into excerpt files, gathering themed data across different transcripts. The analysis evolved iteratively, as Weiss [16] describes, through several coding rounds during which the initial focus and hypothesis were gradually refined, with more and more data fitting into the established codes. That is, using excerpt files, "minitheories" were formulated, based on which new codes were designed and a new coding round was set forth [16].

The initial focus, and hence the basis for planning the question set, was to explore how responsiveness as the "R\&I-type of responsibility" (i.e., forward-looking and uncertainty-receptive) becomes operationalised in an R\&I project. However, it quickly began to emerge from the data analysis that the R\&I context was characterized by a constant dynamic between forward-looking, backward-looking, assertive, and receptive dimensions of responsibility, appearing as dependencies, tensions, synergies, and gaps between different elements of responsibility. This observation lead to the reformulation of initial research question and the application of a new coding set based on Pellizzoni's [12] four responsibility elements (Figure 1). The evolution of the coding sequences is depicted in Appendix B.

Finally, interpretation of the interview results also involved using an adaptation of the "embedded ethicist" method [17]. The setting of "employed ethicist", with one of the authors (the interviewer) working on the case project, also enabled observations on the project's development after the interview period. This allowed some glimpses into the validity of the findings and recommendations of this study in light of later project stages.

\section{Results and Discussion: Meta-Responsibility Outlook on Corporate R\&I}

Through the lens of the responsibility framework (Figure 1), data analysis unveiled a coexistence of forward- and backward-looking, receptive and assertive aspects of responsibility in the team's goals, motivations, concerns, working methods, activities and decision making. Often, different responsibility elements became distinguishable in relation to one another, revealing tensions and trade-offs but also synergies, in between. To better depict and further explore the coexistence of responsibility 
elements, Figure 2 proposes a meta-responsibility map for R\&I. It portrays three major dynamics derived from the case study data between the responsibility elements: accountability-responsiveness, care-responsiveness, and liability-responsiveness.

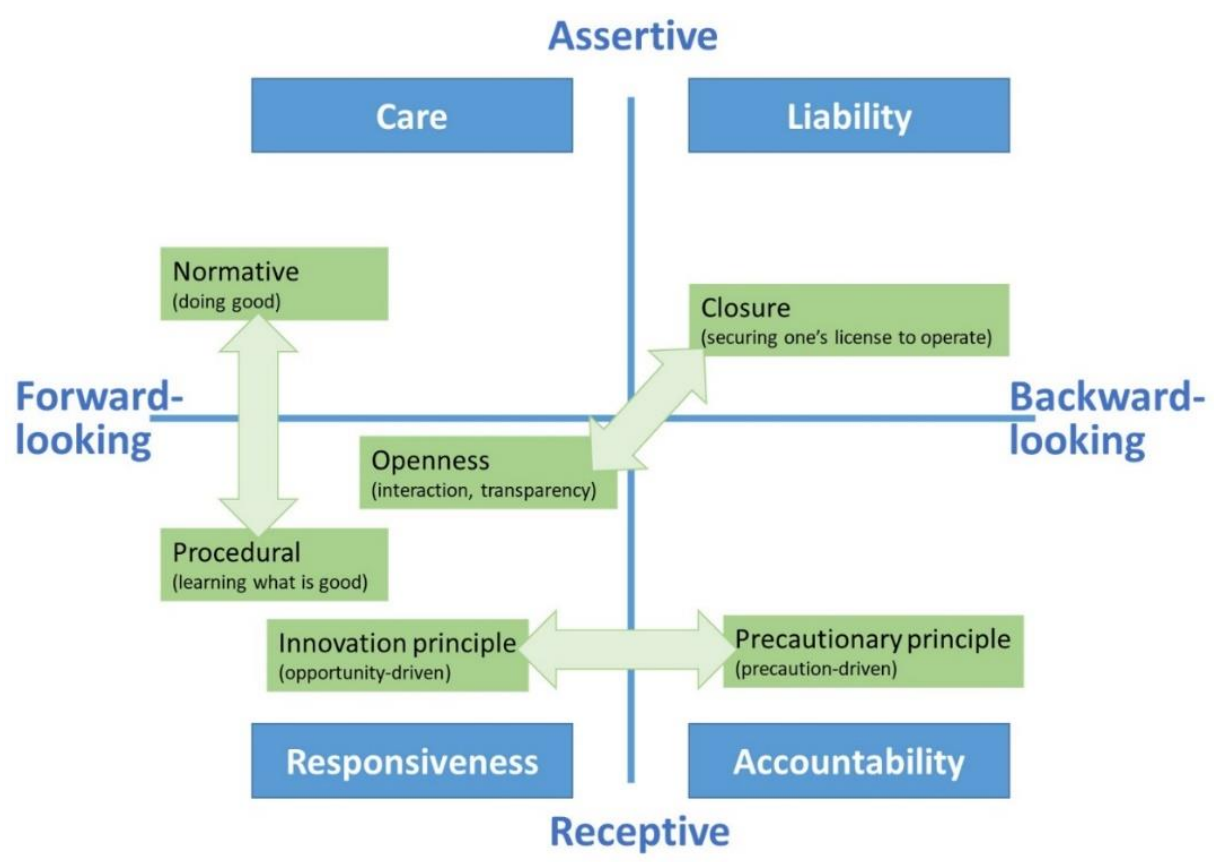

Figure 2. A meta-responsibility map for inventorying responsibilities in R\&I projects.

We identify the following features in the meta-responsibility map that speak for its practical relevance in R\&I, as well as make a theoretical contribution to existing RRI literature on meta-responsibility. First, the map brings various and sometimes contradicting principles, expectations and obligations under a common terminology, responsibility, and thus supports their alignment in R\&I work. In particular, as explicated in Section 2, the map incorporates different stances to coping with the uncertainty faced by R\&I practitioners. Furthermore, the map stems from our empirical finding that the elements of responsibility became most tangible when contrasted (or opposed) to each other in the interviewees' reflections. The focus on dynamics between elements of responsibility, instead of merely focusing on individual elements, can support R\&I teams for instance in situations of decision-making involving contradictory expectations.

That being said, it is evident that there are aspects in responsible innovation, which our framework does not directly address, nor cover to a sufficient degree. There is literature on meta-responsibility that is more targeted, for instance, at specifying who in the R\&I is exactly responsible for whom [7], or, at evaluating the degree to which the identified responsibilities actually become allocated to innovators in R\&I units [4] and contribute to the company's overall performance [11].

The remaining Section 4 presents and discusses the interview results which led to formulation of the meta-responsibility map. First, Table 2 gives an overview on how the conceptual elements of responsibility appeared in light of the practices of Bio2X. It does so by formulating three overall challenges based on the interview responses, which point to the tensions (in Figure 2) between different understandings of responsibility. Further, Table 2 links these challenges with related themes and discussions in the RRI literature. Finally, bringing together theoretical concepts and practice, Table 2 puts into effect the responsibility elements as approaches for managing these challenges. 
Table 2. Overview on how the conceptual elements of responsibility appear in light of the case study.

\begin{tabular}{|c|c|c|c|}
\hline Responsibility Elements at Stake & $\begin{array}{l}\text { Challenge Emerging } \\
\text { from the Case Project }\end{array}$ & Related Themes in RRI & $\begin{array}{l}\text { Approaches for Managing } \\
\text { the Challenge }\end{array}$ \\
\hline Accountability-Responsiveness & $\begin{array}{l}\text { How to strike a balance } \\
\text { between risk-taking and } \\
\text { precaution in early R\&I, } \\
\text { given the uncertainty } \\
\text { about outcomes and } \\
\text { impacts? }\end{array}$ & $\begin{array}{l}\text { Precautionary principle } \\
\text { vs. innovation principle } \\
{[5,12] .} \\
\text { Anticipation of the } \\
\text { impacts of innovation } \\
{[2,3] .}\end{array}$ & $\begin{array}{l}\text { Accountability, as: } \\
\text { Mitigation of uncertainty by } \\
\text { knowing the impacts before } \\
\text { deciding what to do. } \\
\text { Responsiveness, as: } \\
\text { Learning about and } \\
\text { addressing impacts whilst } \\
\text { doing. }\end{array}$ \\
\hline Care-Responsiveness & $\begin{array}{l}\text { How to be sure that R\&I } \\
\text { project is doing the right } \\
\text { thing, given the novelty } \\
\text { of technologies, products } \\
\text { and industrial sector? }\end{array}$ & $\begin{array}{l}\text { Normative vs. } \\
\text { procedural approach to } \\
\text { responsible innovation } \\
{[3,18,19] \text {. }} \\
\text { Reflection on the goals of } \\
\text { innovation }[2,3] .\end{array}$ & $\begin{array}{l}\text { Care, as: Acting based on } \\
\text { given definition for what the } \\
\text { right impact is. } \\
\text { Responsiveness, as: } \\
\text { Practice of actively } \\
\text { (re)assessing what the right } \\
\text { impact is. }\end{array}$ \\
\hline Liability-Responsiveness & $\begin{array}{l}\text { How to accelerate } \\
\text { emergence of a novel } \\
\text { industrial sector, while } \\
\text { also safeguarding one's } \\
\text { own area of operation in } \\
\text { it? }\end{array}$ & $\begin{array}{l}\text { Inclusion, interaction } \\
\text { and transparency, vs. } \\
\text { maintaining information } \\
\text { asymmetry for } \\
\text { competitive advantage } \\
{[13,20] \text {. }}\end{array}$ & $\begin{array}{l}\text { Liability, as: Protecting } \\
\text { oneself against losing one's } \\
\text { assets. } \\
\text { Responsiveness, as: } \\
\text { Openness and dialogue for } \\
\text { advancing joint goals. }\end{array}$ \\
\hline
\end{tabular}

These results are presented and discussed more in detail in the subsections below. Alongside, we discuss the wider applicability of the meta-responsibility map in supporting responsible innovation.

\subsection{Accountability-Responsiveness: Precaution Versus the Innovation Principle}

R\&I, being a highly uncertain activity, is about balancing between risk-taking and exercising precaution. In the RRI context, this dynamic has been brought out as a dichotomy between precautionary and innovation principles [5]. In responsibility terms, these principles appear as manifestations of accountability and responsiveness, respectively. As receptive elements they both acknowledge uncertainty but stand in contrast as to how the uncertainty is addressed. Accountability, as a backward-looking element, favours eliminating risks by knowing the impacts before acting (i.e., precaution), whereas responsiveness as a forward-looking element focuses on opportunities behind the risks and relies on "learning by trying and failing" in seizing them (i.e., innovation). As Dreyer et al. [5] point out, too much precaution may kill or detrimentally slow down innovation, while too much of overhasty trial and error may backfire as well.

\subsubsection{Meta-Responsibility Supports R\&I in Balancing Between Innovation and Precaution}

We suggest that meta-responsibility can help R\&I teams in discussing differing and sometimes opposing views on "risk or precaution" in a constructive way. Both viewpoints can become more understandable as efforts of assuming responsibility over an R\&I project's outcome, in situations of high uncertainty.

The Bio2X team frequently brought up the uncertainty surrounding their early-phase biorefinery project, which indicates an overall receptive mindset. The project was at the stage of exploring several product, partner, and technology options, thus "opening new doors to be able to decide through which to continue". Moreover, many respondents brought up the fact that the small-scale experiments and product prototypes were, always, believed to be only limitedly representative of the eventual large-scale biorefinery. However, the interviewees differed in their views on how to carry on under such uncertainty. On one hand, there was reflection on the risk of giving overly optimistic prospects too soon, e.g., to funders or industrial collaborators: 
"Do we go with too much promising? Now that we're so at the beginning ... building too high expectations."

At the other extreme, some interviewees expressed concern about proceeding too cautiously, slowing down development and encumbering financial resources for the development work:

"I strongly believe in creating challenging and inspiring visions for the future, and (then) doing everything to get there. If you don't dream at all and don't have a good story, it's hard to get people excited, even within the company internally."

"Typically, at this stage in the project, there strikes a fear to promise anything, whereas right now, we should be promising big-time."

In light of meta-responsibility: while some respondents raised a concern about unaccountability (not being able to deliver the indicated impacts), thus taking a backward-looking perspective, there also appeared concerns about unresponsiveness (not addressing an opportunity for fear of failure), marking a more forward-looking stance. Observable in individual remarks during the interview period, this questioning later became more explicit and diverse in the team's internal discussions as Bio2X was shifting from the early project phase closer towards implementation, involving crucial decisions about the eventual biorefinery setting and business model. The right timing for making such decisions became actively debated, in light of how much uncertainty can (and should) be stomached; for instance, when choosing key commercial partners or main end products. In terms of meta-responsibility, seeing the differing viewpoints as complementary aspects of responsibility-already at a very early project phase-could provide a "responsibility frame" for later-stage discussions. For instance, meta-responsibility could come in the form of collective reflection on how to facilitate inherently risky innovations (responsiveness) without "building too high expectations", or, how to take sufficient precaution (accountability) without a "fear of promising anything".

\subsubsection{Meta-Responsibility Shows an Early R\&I Project in Light of Its Eventual Timeframe}

Meta-responsibility helps in comprehending an early-phase R\&I in light of both its current and subsequent responsibilities. In an early-phase R\&I, the forward-looking elements of responsibility are prevalent in probing the impacts of the still-far-ahead outcomes of innovation. At later R\&I stages, initial uncertainty reduces and the temporal focus shifts from the future closer to the present. This enables a wider adoption of also backward-looking responsibilities, such as accountability for profit generation and increasing contractual liabilities. In the case of Bio2X, the meta-responsibility outlook revealed both forward-looking stances of an early-phase project, as well as an "anticipation" of the future's backward-looking responsibilities.

At Bio2X, the interview responses revealed an abundance of management practices (i.e., actions, decisions, working methods) for mitigating perceived uncertainties. Overall, the team's approach in addressing uncertainties clearly inclined towards responsiveness. Activities were distinctly about resolving uncertainties while doing, by piloting through gradual up-scaling; improving process parameters through trying-and-learning, product prototyping and experimentation with industrial manufacturers; and maintaining constant dialogue with key stakeholders such as consumer brand-owners representing the consumer perspective.

"We need to see how the technologies work in upscale. As long as they are concepts on paper or test tubes in the lab, it's not possible to know. We need to pilot and experiment all the way to the end product."

The occurrence of forward-looking practices is logical given Bio2X's early phase. Many respondents also remarked that, in the end, some uncertainty is inevitable in innovation and needs to be accepted, as "successful innovation is also about luck and coincidence", "you can't know everything in advance", and "things also need to happen at the right time". 
On the same note, backward-looking methods such as impact assessment (accountability) were referred to by many Bio2X respondents but seen as largely inapt given the project's early phase, at least in terms of playing out to their fullest extent. For instance, life-cycle analysis (LCA) was not perceived as relevant in the current batch-mode biorefinery pilot, as the properties of material streams (e.g., wastewater volumes and chemicals accumulation) could only be verified later during continuous operation mode.

However, many of Bio2X's activities, during the early phase of the project, appear more coherent when seen as initial attempts to assume "pre-accountability". With the team aware of the approaching backward-looking duties and obligations of the near-commercial phase, they were glimpsing into the project's full-scale impacts with the means available at the time. For example:

"We can simulate a continuous process in batch-mode, to estimate (environmental impacts,) for example water consumption. However, the whole truth will reveal itself only at the demo-scale."

Similarly, in the absence of representative empirical data, the team was conducting a "pre-LCA" study on lignocellulosic textile fibre production, using literature data and benchmarking with the environmental footprints of existing fibre technologies. Moreover, partnering with more established bio-manufactures, having pre-industrial trials, enabled taking considerable leaps from the early stage.

"Our technology suppliers are already in pre-industrial trials; the partners' stage also defines where we are."

It appears that the need for such pre-accountability is accentuated in industrial sectors like Bio2X's. Biorefining is an asset-heavy industry, which implies that mitigating uncertainties via process upscaling demands considerable investments in production equipment and is thus slow and expensive. Furthermore, as bio-based value chains are long multi-party assemblages, it appears practically impossible to make meticulous comparisons between all open product trajectory options, e.g., regarding their environmental footprints. In Bio2X, the number of potential product options was made more manageable by choosing a spearhead product trajectory - textile fibres-whose requirements were given the highest relevance in biorefinery process design. This left a lesser degree of freedom for other fractions, narrowing down product options and enabling a more thorough assessment of at least some product pathways, while positioning the assessment of others for later stages.

Table 3 summarises the practices for mitigating uncertainties that were referred to by the Bio2X interviewees, some of which have been discussed above. In line with Table 2:

- (A) is used to mark practices that are characteristically about accountability, in that they focus on knowing impacts before deciding what to do.

- (R) marks practices of responsiveness, as learning about and addressing impacts whilst doing.

- In addition, (R/A) refers to practices that do not clearly fall into either of the above, but rather mediate in between (i.e., "pre-accountability" as anticipation of future accountabilities).

In summary, meta-responsibility broadens the scope of responsibility during an early-phase R\&I in that the activities of anticipating future responsibilities, beyond immediate responsibilities, also become encompassed. Regarding RRI as a meta-responsibility approach, this perspective makes RRI more attentive to the (near-)commercial responsibilities of corporate R\&I, which, as pointed by Dreyer et al. [5], have so far remained poorly addressed in RRI. In particular, the mindset of "pre-accountability" in cases like Bio2X is a call for RRI proponents to advocate and further develop tools of anticipation, to support corporate R\&I in exploring their future responsibilities for the impacts of the prospective full-scale innovation. 
Table 3. Management practices for mitigating uncertainty regarding an R\&I project's outcomes.

\begin{tabular}{|c|c|c|}
\hline $\begin{array}{l}\text { (R) Responsiveness: Learning } \\
\text { about and Addressing Impacts } \\
\text { Whilst Doing }\end{array}$ & $\begin{array}{l}\text { (R/A) Mediating Practices: } \\
\text { Anticipation of Future } \\
\text { Accountability }\end{array}$ & $\begin{array}{c}\text { (A) Accountability: Knowing the } \\
\text { Impacts Before Deciding What to } \\
\text { Do }\end{array}$ \\
\hline \multicolumn{3}{|c|}{ Practices related to R\&I management and strategies } \\
\hline $\begin{array}{l}\text { Iterative rather than linear } \\
\text { project model } \\
\text { - } \quad \text { Learning-by-doing, gradually } \\
\text { focusing hypotheses } \\
\text { - Many simultaneous product/ } \\
\text { process trajectories (plan-B's) } \\
\text { Design thinking: inclusion of } \\
\text { sustainability criteria in early } \\
\text { process design }\end{array}$ & $\begin{array}{l}\text { - Choosing one spearhead } \\
\text { product trajectory (to narrow } \\
\text { down options) } \\
\text { - Temporal prioritisation: only } \\
\text { few product trajectories at } \\
\text { a time }\end{array}$ & $\begin{array}{l}\text { - Stage-gate process model } \\
\text { including showstoppers }\end{array}$ \\
\hline \multicolumn{3}{|c|}{ Practices related to piloting and experimentation } \\
\hline $\begin{array}{l}\text { - } \quad \text { Piloting biorefinery } \\
\text { Prototyping and } \\
\text { experimentation with } \\
\text { downstream } \\
\text { product manufacturers } \\
\text { Proceeding gradually } \\
\text { towards more challenging } \\
\text { raw materials/products }\end{array}$ & $\begin{array}{l}\text { - Simulation of continuous } \\
\text { process in small-scale batches }\end{array}$ & \\
\hline \multicolumn{3}{|c|}{ Practises related to assessments and evaluations } \\
\hline $\begin{array}{ll}\text { - } & \text { Studying consumer and } \\
\text { societal trends } \\
\text { - } & \text { Market studies }\end{array}$ & $\begin{array}{l}\text { - } \quad \text { Pre-LCA" based on } \\
\text { estimated and literature data } \\
\text { Applying higher } \\
\text { (sustainability) standards for } \\
\text { novel biorefinery than in the } \\
\text { existing ones }\end{array}$ & $\begin{array}{l}\text { Full LCA (close to the } \\
\text { implementation phase) } \\
\text { Benchmarking to existing } \\
\text { operations in the sector } \\
\text { Following certificates } \\
\text { and standards }\end{array}$ \\
\hline \multicolumn{3}{|c|}{ Practices related to partnerships } \\
\hline $\begin{array}{l}\text { Open communication } \\
\text { with stakeholders } \\
\text { Fostering trust } \\
\text { among partners }\end{array}$ & $\begin{array}{l}\text { - Collaboration with partners } \\
\text { having (pre-)industrial trials }\end{array}$ & $\begin{array}{ll}\text { - } & \text { Auditing } \\
\text { - } & \text { Requiring certificates } \\
\text { and standards }\end{array}$ \\
\hline \multicolumn{3}{|c|}{ PDealing with residual uncertainty } \\
\hline $\begin{array}{l}\text { - Accepting “you cannot know } \\
\text { in advance" } \\
\text { - } \quad \text { Leaving space for luck } \\
\text { and coincidence } \\
\text { - } \quad \text { Trusting one's partners } \\
\text { - } \quad \text { Trusting that over time, } \\
\text { technological development } \\
\text { will solve uncertainties }\end{array}$ & & \\
\hline
\end{tabular}

\subsection{Care-Responsiveness: A Normative vs. Procedural Approach to Responsible Innovation}

R\&I, as a future-oriented activity, is focused on transforming the current state of affairs towards what is seen as more desirable. However, determining what a desirable outcome is may not be that straightforward. While the dynamic between accountability and responsiveness relates to knowing about the impacts of an innovation trajectory, the interplay between care and responsiveness involves a more profound questioning as to whether one's understanding of what constitutes good impact is, at the outset, "correct" or "right" (e.g., corresponding to societal perceptions or consumer needs). 
As summarized by Blok et al. [18], RRI builds on two fundamental approaches in determining what a good impact of innovation is. The first one is the normative approach by von Schomberg [19], applying commonly agreed norms and principles as "normative anchor points" for R\&I, such as "sustainability" and "social justice" in the European Union treaties, or a set of sustainability goals in a corporate strategy. In contrast, the procedural approach promoted by Owen et al. [3] highlights the need for innovators to continuously reassess the right impacts of innovation, e.g., by dialogue with its stakeholders, with norms less set in stone. In light of the responsibility framework, we suggest that the normative approach is an alias for care, whereas the procedural approach resonates with responsiveness. Being forward-looking elements, they are both driven by an aspiration to improve the current state of affairs, but whereas the assertive element of care is welcoming to fixed definitions for right impacts, responsiveness as a receptive element emphasizes the importance of constant checks for staying on-track towards what is a desirable innovation output.

Practical R\&I work involves balancing between the normative and procedural. For example, highly novel and disruptive innovations may bring about societal disagreements regarding their desirability, calling for a broader and inclusive reflection on needs and impacts e.g., through stakeholder dialogue [21]. Other occasions may favour a more normative approach. Some innovations enjoy a broader social consensus regarding their desirability [18]. Moreover, stakeholder engagement is not a cure-all, as different views can conflict without providing a clear trajectory, or for practical reasons such as it being too time-consuming [22]. Furthermore, stakeholders may be unwilling to become involved in R\&I activities [22].

\section{Meta-Responsibility to Expose Implicit Concerns Regarding R\&I Outcomes}

We propose meta-responsibility as one means to maintain attention on an R\&I project's wider impacts. It can trigger discussion on implicit concerns and reservations as to whether an R\&I project is "doing the right thing" and aid in determining whether to adjust the project's goals and directions. In this, meta-responsibility acknowledges both the normative (knowing what is a good impact) and the procedural (learning what is a good impact) standpoints as strategies for taking responsibility for a project's trajectory and can stimulate reflection on their right balance.

In interviewing Bio2X members, the theme of "good impacts" was broached by inquiring about wider societal impacts that the respondents envisioned the biorefinery would have in the future, and how such impacts (e.g., on environment, employment) were considered and discussed overall in the project. Both normative and procedural standpoints were expressed in the interview responses. On one hand, corporate sustainability strategy provided a normative anchor point for many respondents:

"The company's strategy is to be a clean technology company and to boost the use of new technologies that burden nature and society less than the existing ones. In this way, Bio2X was actually born and our meaning comes from there. We are serving that vision."

"The company's sustainability goals are very progressive and ambitious and well in line with my own (values)."

On the other hand, among some respondents the interviews triggered a more receptive (procedural) reflection on the difficulty of exhaustively defining what "sustainable" in biorefining entails. This corresponds to findings by Asveld and Stemerding [21] regarding ambiguity in the bioeconomy: Complex indirect land-use impacts coupled with diverging values and priorities make it hard to falsify or prioritise one sustainability argument over another. One interviewee had observed such ambiguity in the argumentation for and against using stem wood in bio-based manufacturing:

"Building the concept (of wood-based biorefinery) sustainably, when you see it on paper it's 'OK we can go with this', but how to justify it to ourselves and to stakeholders-it's a challenge in my opinion." 
Moreover, the consumer demand for bio-based manufactured products was perceived as somewhat ambiguous owing to their general novelty:

"Compared to biofuels, there are no clear existing markets, regulations, and obligations (for bio-based manufacturing). That makes the discovery of the demand-side motivation not as clear as with fuels."

Furthermore, while most respondents brought up sustainability as an important motivator for the project, it was also contemplated whether-somewhat paradoxically—sustainability as a strategic imperative was so much "in the spine" that it had become an axiom.

"Environmental aspects form a basic motivation for what we do. Maybe we don't think about it every day; it's so much in our spine."

"I've noticed that we tend to take for granted that things are responsible."

Altogether, the very act of interviewing sparked reflection among the team members on the project's initial assumptions and wider societal impacts. In that sense, interviewing became a practice of meta-responsibility, supporting responsible R\&I by giving voice to implicit concerns about an R\&I project's goals and directions. Here, meta-responsibility enhances reflection on the impacts of R\&I-a foundational aim in RRI and in related approaches such as Midstream Modulation [23].

Besides reflection, meta-responsibility can also aid in identifying management practices for keeping the innovation "on track" with fulfilling positive societal impacts. In the Bio2X case, an array of both normative and procedural means was identifiable. Normative anchor points included, for instance, fixing the project's aims to corporate strategy-level sustainability guidelines, which for their part are rooted in addressing Grand Global Challenges such as climate change. Regarding the procedural approach, stakeholder involvement of brand-owners was identified as a means to discover consumer stances on novel bio-based products. However, alongside this, it was also mentioned that normative strategic guidelines are needed as "consumers may want all shiny and glittery, and such products can be difficult to (sustainably) recycle".

Interviewees also pointed out that ultimately some uncertainty is inevitable in R\&I, which emphasises the importance of open communication:

"Is there something we don't see ourselves that leaks out in terms of sustainability? To recognize stretches of weak ice and speak them out: 'these are the handicaps of our processes'. Someone will dig them out anyway."

Finally, technological development appeared as a means to bypass some of the observed ambiguity regarding sustainability, for instance, in the use of stem wood in bio-based manufacturing:

"There is a lot of recycled wood in the world. Could it also be used as raw material in our processes?

Why wouldn't it be a good time to start a small study, first the literature and then the experimental."

This particular reflection became an incentive for designing a study on the use of recycled wood in the fractionation process, which was eventually conducted later in the project. In retrospect, this exemplifies how meta-responsibility can create systematics for identifying and then addressing "stretches of weak ice", particularly during early stages when innovations are still well amenable to modifications.

Table 4 summarises the management practices referred to in Bio2X for keeping on track with the "right impacts" of innovation, some of which have been discussed above. In line with Table 2:

- (C) is used to mark practices that are characteristically about care, in that they justify actions based on knowing in advance what a right impact is.

- (R) marks practices of responsiveness, in the form of actively (re)assessing what a right impact is.

- In addition, (R/C) refers to practices that do not clearly fall into either of the above, but rather mediate in between (i.e., normative-procedural interaction). 
Table 4. Management practices for determining the "rights impacts" towards which to steer R\&I.

\begin{tabular}{|c|c|c|}
\hline $\begin{array}{l}\text { (R) Responsiveness: Actively } \\
\text { (re-) Assessing What the Right } \\
\text { Impact is }\end{array}$ & $(\mathrm{R} / \mathrm{C})$ Mediating Practices & $\begin{array}{l}\text { (C) Care: Acting Based on Given } \\
\text { Definitions for What the Right } \\
\text { Impact is }\end{array}$ \\
\hline \multicolumn{3}{|c|}{ Practices related to R\&I management and strategies } \\
\hline $\begin{array}{l}\text { Iterative rather than linear } \\
\text { project model } \\
\text { Learning-by-doing, } \\
\text { gradually focusing goals }\end{array}$ & $\begin{array}{l}\text { - Normative-operational } \\
\text { interaction: Collaboration } \\
\text { between the R\&I, Strategy, } \\
\text { and Sustainability units } \\
\text { - In situations of high } \\
\text { uncertainty, apply } \\
\text { higher-level standards "just } \\
\text { in case" }\end{array}$ & $\begin{array}{l}\text { - Anchoring of the project's } \\
\text { aims to corporate } \\
\text { strategy-level guidelines } \\
\text { Corporate strategy anchored } \\
\text { to Global Grand Challenges } \\
\text { (e.g., climate change) } \\
\text { - Benchmarking: Anchoring } \\
\text { the project's aims to the } \\
\text { standards of the } \\
\text { industrial sector }\end{array}$ \\
\hline \multicolumn{3}{|c|}{ Practices related to stakeholder engagement } \\
\hline $\begin{array}{l}\text { Involving stakeholders for } \\
\text { mutual learning regarding } \\
\text { the R\&I project } \\
\text { Applying local expertise for } \\
\text { understanding diverging } \\
\text { needs at different locations }\end{array}$ & $\begin{array}{l}\text { Involving brand-owners (or } \\
\text { other established actors) as } \\
\text { representatives of consumer/ } \\
\text { societal demands } \\
\text { Checking from stakeholders } \\
\text { that the project's aims are } \\
\text { communicated clearly (e.g., } \\
\text { to end consumers) } \\
\text { Learning from external } \\
\text { experts: consultants, } \\
\text { attending conferences }\end{array}$ & $\begin{array}{l}\text { - Involving stakeholders for } \\
\text { informing them about the R\&I } \\
\text { project }\end{array}$ \\
\hline \multicolumn{3}{|c|}{ Practices related to assessments and evaluations } \\
\hline $\begin{array}{l}\text { - Team/self-reflection on what } \\
\text { is responsible/ sustainable } \\
\text { - Consumer trend / market } \\
\text { demand assessments }\end{array}$ & & \\
\hline \multicolumn{3}{|c|}{ Dealing with residual uncertainty } \\
\hline $\begin{array}{l}\text { - Awareness that "we do not } \\
\text { know everything } \\
\text { - Accepting "good enough" } \\
\text { - Openness about unclear and } \\
\text { ambiguous issues } \\
\text { Technological development } \\
\text { to get around dilemmas and } \\
\text { disagreements about } \\
\text { right impacts }\end{array}$ & & \\
\hline
\end{tabular}

\subsection{Liability-Responsiveness: Protecting One's Assets vs. Speeding up Sectoral Change}

From its outset, the private sector is characterised by information and power asymmetries that are sought out and maintained for the sake of securing competitive advantage. Somewhat contrary, RRI initially defines responsible innovation as a "transparent, interactive process by which societal actors become mutually responsive to each other with a view to the (ethical) acceptability, sustainability, and societal desirability of the innovation process and its marketable products" [19] (p. 19). Bringing together these two principles has been a major point of contention in the RRI studies on private sector R\&I [13]. Openness "creates an inherent feeling of lack of control over the processes and results of the innovation", and interaction can be restricted by the risk of knowledge (ownership) leakage to competitors [20] (p. 151). However, reducing information asymmetry can also bring about considerable 
benefits. Sharing information, resources, and partnerships can accelerate sectoral renewal beyond what is achievable by one company alone, for example, in transforming an entire sector towards more sustainable technologies and practices $[9,20]$. The value of stakeholder interaction on a product's success is well acknowledged among companies. For example, different forms of Open Innovation are well-known working methods in some industries [24].

\section{Meta-Responsibility in Bridging Between Societal Goals and Competitive Advantage}

RRI has recognised the difficulty in bringing together closure and openness in R\&I but so far provides little advice on how to address it. In light of this case study, we suggest that meta-responsibility can facilitate responsible innovation by bringing the co-existing, and somewhat conflicting, tendencies of closure and openness under the terminology of responsibility.

While Bio2X was building the biorefinery concept and its emerging value chains on the basis of active collaboration between several institutions (companies, start-ups and research institutes), it also identified certain risks in this approach. The need for finding balance between closure and openness was voiced most explicitly by one interviewee:

"When you operate in (a business) ecosystem, you accept that not everything is yours. But how to secure what's yours sufficiently so that you have a freedom to operate in where you build your key success factors?"

On the one hand, many interviewees highlighted the fact that the emergence of bio-based manufacturing sector would be extremely slow without "linking actors and scaling up technologies together". At this point, the company's role as an "accelerator" was brought up by most respondents. On the other hand, the accelerator role was seen to be accompanied by the risk of losing ideas, generated knowledge, and decision-making power beyond the company's control. Some of the respondents brought up concerns about "someone taking our ideas and blocking us out from the sector-in case we're the only one trying to open up". For one respondent, this risk was especially pronounced given the early phase of the project-while the team is still evaluating several product portfolios and business model options, they simultaneously "need to look 10-20 years ahead to be able to reserve what you want for yourself".

In view of meta-responsibility, the interplay between openness and closure resonates with that found between responsiveness and liability. Responsiveness takes responsibility for progressing joint societal needs and goals, in Bio2X's case, the acceleration of sectoral change towards bio-based production, via promoting information sharing and interaction between industrial manufacturers, consumer brand-owners, and other stakeholders. Liability imposes responsibility for protecting oneself against losing one's assets, to secure the legal and contractual freedom to operate by, e.g., restricting information sharing and protecting intellectual property through patents (and respecting others' intellectual property to avoid legal measures).

We argue that meta-responsibility can facilitate responsible R\&I in that it recognises both sectoral acceleration and preserving one's own possessions as displays of responsibility (to shareowners, further to society, and to other legal entities). On this basis, meta-responsibility can support R\&I teams in recognising tensions and synergies amid those objectives and, subsequently, in applying management practices for balancing between. Similar to "risk or precaution", this thematic also became more explicit in the Bio2X team's discussions only after the interview period, fuelled by the approach of the pre-commercial phase involving crucial choices between biorefinery business model, process, and partner options. For instance, the trade-off of speeding up the biorefinery upscaling (Bio2X's role in the value chains being narrower) and that of generating and applying intellectual property rights for Bio2X (taking more time) became actively discussed. With meta-responsibility, this and similar questions could already be systematically identified and explored at earlier R\&I phases, to support decision making at later stages. 
Many management practices already exist in corporate R\&I for balancing between openness (responsiveness) and closure (liability) and were in use by Bio2X. For instance, regarding liability, the Bio2X team operated under Non-Disclosure Agreements (NDAs) and Material Transfer Agreements (MTAs) whenever the produced lignocellulosic fractions were being tested by industrial manufacturers.

"(Openness) requires securing our ideas and projects, be it patenting or other agreements, or NDA."

Additionally, more responsive approaches and tools were identified and further ideated during the interviews:

"We could have cases functioning as open innovation. For example, with cellulose-based textiles, if we incorporate them into a publicly funded project and involve a number of start-ups and create (a business) ecosystem or company clusters."

Also tied to responsiveness is the importance of building trust among stakeholders, another factor emphasised by many respondents. In line with Dreyer et al. [5] trust is an important accelerator in risky innovations, promoting "lean regulation and low barriers for scaling-up" (p. 10), as opposed to defining every detail through contracts. Finally, communicating a strategy of openness and encouraging others to do the same was mentioned as one means of mitigating the risks of losing control:

"(If we) speak out about the openness strategy as much as possible and that becomes a generally accepted approach, like 'we are ready for it, are you?' then it would at least mitigate the risk that someone would dare to steal from another."

As a mediating practice between liability and responsiveness, "selective openness" appeared where certain topics are promoted jointly by the partner network while others remain exclusive:

"We clearly define what is our core, our spearhead, and what is free for others, thus setting limits for competition."

For instance, sustainability goals were seen as joint terrain and "an easily shareable topic", with which it is also easy to approach potential new partners. In light of earlier RRI studies on stakeholder engagement, selective openness can be of joint interest as R\&I's stakeholders are often motivated not to become too closely involved in projects [22]. This setting opens opportunities for RRI to further develop practices of selective openness for corporate R\&I that are in line with RRI's principles of inclusion and deliberation.

Table 5 summarises identified management practices in Bio2X for accelerating the formation of the bio-based manufacturing sector, while safeguarding its own area of operation within it. In line with Table 2:

- (L) is used to mark practices that are characteristically about liability, in that they focus on protecting oneself against losing one's assets.

- (R) marks practices of responsiveness, in terms of fostering openness and dialogue for advancing joint goals.

- In addition, $(\mathbf{R} / \mathbf{L})$ is used with mediating practices (selective openness). 
Table 5. Practices for managing a corporate R\&I project within (and as part of) an emerging industrial sector.

\begin{tabular}{|c|c|c|}
\hline $\begin{array}{l}\text { (R) Responsiveness: Openness } \\
\text { and Dialogue for Advancing } \\
\text { Joint Goals }\end{array}$ & (R/L) Mediating Practices & $\begin{array}{l}\text { (L) Liability: Protecting Oneself } \\
\text { Against Losing One's Assets }\end{array}$ \\
\hline \multicolumn{3}{|c|}{ Practices related to partnerships } \\
\hline $\begin{array}{l}\text { - Societal and sustainability } \\
\text { goals as a shared terrain } \\
\text { among partners } \\
\text { - } \quad \text { Building trust } \\
\text { between partners } \\
\text { - } \quad \text { Right to opt out } \\
\text { from collaboration }\end{array}$ & $\begin{array}{l}\text { Selective openness: } \\
\text { Openness among partners } \\
\text { except for the } \\
\text { core competences } \\
\text { Clearly communicating what } \\
\text { the core is and what is } \\
\text { shareable with (or free } \\
\text { for) others }\end{array}$ & $\begin{array}{l}\text { - Contractual measures (e.g., } \\
\text { NDA) }\end{array}$ \\
\hline \multicolumn{3}{|c|}{ Practices related to $R \& I$ management and strategies } \\
\hline $\begin{array}{l}\text { - } \quad \text { Open innovation models } \\
\text { - } \quad \text { Communicating the strategy } \\
\text { of openness }\end{array}$ & $\begin{array}{l}\text { - Clearly defining what the core } \\
\text { is and what is shareable with (or } \\
\text { free for) others }\end{array}$ & $\begin{array}{l}\text { - Securing ideas } \\
\text { through patents } \\
\text { Increasing technical } \\
\text { knowledge about } \\
\text { core technologies } \\
\text { Enhancing technology } \\
\text { ownership via investments }\end{array}$ \\
\hline \multicolumn{3}{|c|}{ Practices related to assessments and evaluations } \\
\hline & $\begin{array}{l}\text { - Scenarios of sectoral and } \\
\text { market development } \\
\text { Reflection on the project's } \\
\text { vision and role in the } \\
\text { emerging business ecosystem }\end{array}$ & - IPR landscape assessments \\
\hline
\end{tabular}

\section{Conclusions}

In this paper we developed a meta-responsibility map for facilitating responsible innovation in corporate R\&I. We began by itemising the extensive concept of "responsibility" into elements of care, liability, accountability, and responsiveness, with the framework by Pellizzoni [12], and further adapted this framework into being more attentive to R\&I as a highly uncertain and future-oriented environment. With this framework in hand, using a case study, we set out to explore how theoretically formulated responsibility elements become operationalised in a corporate R\&I project. In the resulting analysis, elements of responsibility regularly appeared in interaction with one another, revealing tensions and trade-offs but also synergies in between. This finding led us to develop a meta-responsibility map elaborating the dynamics between responsibilities in corporate R\&I settings.

We conclude that the meta-responsibility map can help R\&I personnel to deal with the inherent uncertainty of R\&I in a responsible way, in that it brings various and sometimes contradicting principles, expectations, and obligations under a common terminology of responsibility and thus supports their alignment in R\&I work. In this particular case study, meta-responsibility brought to light challenges as well as solutions related to (i) balancing risk and precaution, (ii) exposing and addressing concerns about the goals and impacts of innovation, (iii) accelerating sectoral transition whilst securing one's own competitive advantage in it. With meta-responsibility, we were able to capture early voicings of these themes among the interviewees that subsequently became frequent topics of discussion during later project stages. Here, we propose that meta-responsibility adopted into early-phase R\&I can support R\&I throughout its trajectory, by bringing systematics for identifying different responsibilities, supporting deliberation on them, and mobilising practices for balancing in between them. As exemplified in Tables 3-5, companies already possess a wealth of approaches and methods for addressing different 
aspects of responsibility. Meta-responsibility can become a management approach for thoughtful application of these practices across the entire innovation process.

Regarding implications on RRI, the meta-responsibility map can enhance RRI's theoretical integrity as it links some of RRI's key themes and discussions with the terminology of responsibility. It does so by presenting the dichotomies of normative-procedural, precaution-innovation, and closure-openness as addressing different elements of responsibility. Secondly, meta-responsibility enhances RRI's relevance in corporate settings as it encompasses both early-phase (often forward-looking) and near-commercial (increasingly backward-looking) responsibilities, the latter of which have so far remained narrowly addressed in RRI. Lastly, systematic inventorying of responsibilities in an R\&I project can pinpoint specific missing elements, enabling a more targeted and context-sensitive application of RRI's toolkit for increasing anticipation, reflection, and inclusion in R\&I activities.

Our study obviously has its limitations. First, given its exploratory nature, the scope, result analysis, and formulation of meta-responsibility developed iteratively. This implies, for instance, that the eventual research question was somewhat different than the original one used for designing the interview questionnaire. Adopting meta-responsibility in further case studies would make the approach theoretically more solid (by enriching understanding about interactions between responsibility elements) and empirically more diverse (by encompassing different types of companies, R\&I project models and phases, as well as industrial sectors). Secondly, one of the paper's authors is employed in the case project under study, which brings in the question about the influence of this position in the research design, interviewing, and interpretation of the results. Having both benefits and drawbacks, the role of an "employed ethicist" - in parallel to that of an embedded ethicist [17] or embedded humanist [23] — definitely deserves further deliberation as a mode of conducting case studies and qualitative research.

Finally, the study brought out further research topics that were not possible to address within the limits of one paper. One such topic is to render the complex notion of "co-responsibility" more digestible by approaching it through meta-responsibility. This would enable explorations on how different elements of responsibility are distributed between different organisations along an entire product value chain or between units of an individual company. Another topic for RRI would be to further explore how the corporate raison d'être, accountability for profit generation, coexists with other aspects of responsibility in R\&I projects.

Author Contributions: Conceptualization, M.S.; methodology and validation, M.S. and L.A.; formal analysis, investigation, and data curation M.S.; resources, M.S., L.A.; writing-original draft preparation, M.S.; writing-review and editing, M.S., L.A., and P.O.; visualization, M.S.; supervision and funding acquisition L.A. and P.O.; project administration, M.S. All authors have read and agreed to the published version of the manuscript.

Funding: This research was funded by TU Delft and by the European Union within the 7th Framework Programme SYNENERGENE project, grant number 321488.

Conflicts of Interest: The authors declare no conflict of interest.

\section{Appendix A Indicative Interview Questions}

1. How would you briefly describe the project and its aims?

2. What is your role and area of responsibility in the project?

3. What inspires and motivates you in your work?

4. What kind of uncertainties does this kind of project face?

5. How are such uncertainties being addressed in the project?

6. What is corporate responsibility in your understanding?

7. In your opinion, how does the project link to corporate responsibility?

8. What kind of positive impacts do you foresee that the project could deliver in society and in the environment?

9. Is there something that concerns you regarding societal and environmental impacts of this project? 
10. In matters of corporate responsibility, what kind of collaboration is needed between this project and the other units or functions the company?

11. At which stage is the project at the moment? (A description of R\&I project stages is shown to interviewee, including exploration stage (applied research), development stage (pilot and demonstration), implementation stage (delivering value to consumers and society).)

12. In general, how is it to make decisions at this stage of the project?

13. Do you come up with a situation, where an expected positive societal or environmental impact has led to a decision affecting the project's direction?

14. Do you come up with a situation, where an expected negative societal or environmental impact has led to a decision affecting the project's direction?

15. Overall, how far do you think that a project like this should consider its wider societal impacts?

16. Thinking ahead, are there some issues related to wider societal impacts that will impact decision making at the coming steps of the project?

17. How have wider societal impacts been considered in (i) strategy and business model generation, (ii) at the team's internal discussions, and (iii) in relation to technical process development?

18. What stakeholders can you name for this project? (a definition of stakeholders as "those that can affect or be affected by the project' being shown to interviewee).

19. Of these, who do you consider as main stakeholders, i.e., who have the widest impact in the project?

20. How do you work with the main stakeholders? (For example, are they somehow involved in the decision making?)

21. Do you recall situations, where societal or environmental questions have been discussed with stakeholders?

22. How about the other stakeholders that you mentioned (at Question 18), how are those taken into consideration in the project?

23. Can you still think of some groups who you have not identified (at Question 18) but who could still be affected by the project's outcome in the future?

24. Ideally, what should happen to a product of this biorefinery, when launched to consumers?

25. Finally, is there something else that you would like to bring out?

\section{Appendix B Evolution of the Coding Sequences During the Analysis of the Interview Data}

Figure A1 illustrates the iterative development of research questions and hypotheses during the data analysis and points out the result output from each stage of iteration.

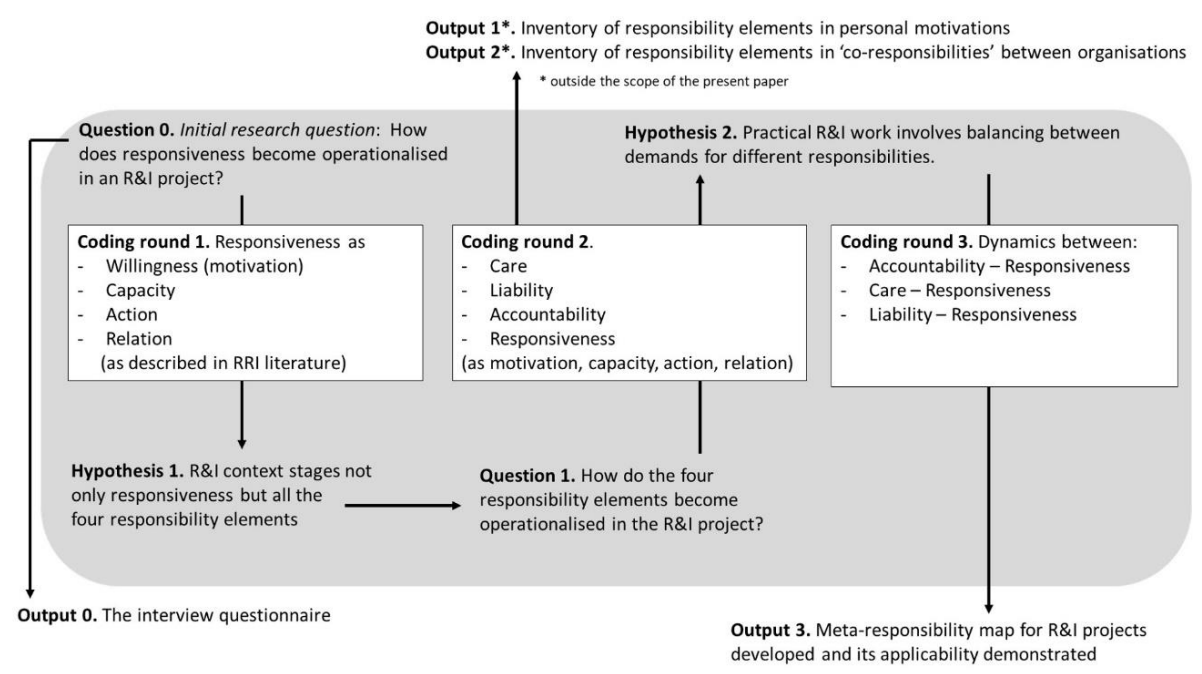

Figure A1. Evolution of the coding sequence during the analysis of the interview data. 


\section{References}

1. Van de Poel, I.; Asveld, L.; Flipse, P.; Klaassen, V.; Scholten, V.; Yaghmaei, E. Company Strategies for Responsible Research and Innovation (RRI): A Conceptual Model. Sustainability 2017, 9, 2045. [CrossRef]

2. Lubberink, R.; Blok, V.; van Ophem, J.; Omta, O. Lessons for Responsible Innovations in the Business Context: A Systematic Literature Review of Responsible, Social and Sustainable Innovation practices. Sustainability 2017, 9, 721. [CrossRef]

3. Owen, R.; Stilgoe, J.; Macnaghten, P.; Gorman, M.; Fisher, E.; Guston, D. A framework for responsible innovation. In Responsible Innovation: Managing the Responsible Emergence of Science and Innovation in Society; Owen, R., Bessant, J., Heintz, M., Eds.; John Wiley and Sons, Ltd.: Chichester, UK, 2013; pp. 27-50. [CrossRef]

4. Van de Poel, I.; Sand, M. Varieties of responsibility: Two problems of responsible innovation. Synthese 2018, 195, 1-19. [CrossRef]

5. Dreyer, M.; Chefneux, L.; Goldberg, A.; von Heimburg, J.; Patrignani, N.; Schofield, M.; Shilling, C. Responsible Innovation: A Complementary View from Industry with Proposals for Bridging Different Perspectives. Sustainability 2017, 9, 1719. [CrossRef]

6. Pellé, S.; Reber, B. Responsible innovation in the light of moral responsibility. J. Chain Netw. Sci. 2015, 15, 107-117. [CrossRef]

7. Timmermans, J.; Yaghmaei, E.; Stahl, B.C.; Brem, A. Research and innovation processes revisited: Networked responsibility in industry. Sustain. Account. Manag. Policy J. 2017, 8, 307-334. [CrossRef]

8. Zwart, H.; Landeweerd, L.; Van Rooij, A. Adapt or perish? Assessing the recent shift in the European research funding arena from 'ELSA' to 'RRI'. Life Sci. Soc. Policy 2014, 10, 11. [CrossRef] [PubMed]

9. Chatfield, K.; Iatridis, K.; Stahl, B.C.; Paspallis, N. Innovating Responsibly in ICT for Ageing: Drivers, Obstacles and Implementation. Sustainability 2017, 9, 971. [CrossRef]

10. Stahl, B.C. Responsible research and innovation. The role of privacy in an emerging framework. Sci. Public Policy 2013, 40, 708-716. [CrossRef]

11. Stahl, B.C.; Obach, M.; Yaghmaei, E.; Ikonen, V.; Chatfield, K.; Brem, A. The Responsible Research and Innovation (RRI) Maturity Model: Linking Theory and Practice. Sustainability 2017, 9, 1036. [CrossRef]

12. Pellizzoni, L. Responsibility and Environmental Governance. Environ. Politics 2004, 13, 521-565. [CrossRef]

13. Blok, V.; Lemmens, P. The Emerging Concept of Responsible Innovation. Three Reasons Why It Is Questionable and Calls for a Radical Transformation of the Concept of Innovation. In Responsible Innovation 2: Concepts, Approaches, and Applications; Koops, B.-J., Osterlaken, I., Romijn, H., Swierstra, T., van den Hoven, J., Eds.; Springer: Cham, Switzerland, 2015; Volume 2, pp. 19-35. [CrossRef]

14. Noorman, M.; Swierstra, T.; Zandbergen, D. Questioning the normative core of RI: The challenges posed to stakeholder engagement in corporate setting. In Responsible Innovation 3: A European Agenda? Asveld, L., van Dam-Mieras, R., Swierstra, T., Lavrijssen, S., Linse, K., van den Hoven, J., Eds.; Springer: Dordrecht, the Netherlands, 2017; pp. 231-249. [CrossRef]

15. Nielsen, M.V. The concept of responsiveness in the governance of research and innovation. Sci. Public Policy 2016, 43, 831-839. [CrossRef]

16. Weiss, R.S. Learning from Strangers: The Art and Method of Qualitative Research; The Free Press: New York, NY, USA, 1994.

17. The PRISMA Responsible R\&I Toolkit. Available online: http://www.rri-prisma.eu/rri-tool/embedded-ethicist (accessed on 5 October 2019).

18. Blok, V.; Tempels, T.; Pietersma, E.; Jansen, L. Exploring Ethical Decision Making in Responsible Innovation: The Case of Innovations for Healthy Food. In Responsible Innovation 3: A European Agenda? Asveld, L., van Dam-Mieras, R., Swierstra, T., Lavrijssen, S., Linse, K., van den Hoven, J., Eds.; Springer: Dordrecht, The Netherlands, 2017; pp. 231-249. [CrossRef]

19. Von Schomberg, R. A vision of responsible innovation. In Responsible Innovation: Managing the Responsible Emergence of Science and Innovation in Society; Owen, R., Bessant, J., Heintz, M., Eds.; John Wiley and Sons, Ltd.: Chichester, UK, 2013; pp. 51-74.

20. Blok, V.; Hoffmans, L.; Wubben, E.F. Stakeholder engagement for responsible innovation. J. Chain Netw. Sci. 2015, 15, 147-164. [CrossRef] 
21. Asveld, L.; Stemerding, D. Social learning in the bioeconomy: The Ecover case. In Experimentation Beyond the Laboratory: New Perspectives on Technology in Society; van de Poel, I., Asveld, L., Mehos, D.C., Eds.; Routledge: London, UK, 2017; pp. 103-124.

22. Sonck, M.; Asveld, L.; Landeweerd, L.; Osseweijer, P. Creative tensions: Mutual responsiveness adapted to private sector research and development. Life Sci. Soc. Policy 2017, 13, 14. [CrossRef] [PubMed]

23. Flipse, S.M.; van der Sanden, M.C.A.; Osseweijer, P. Midstream Modulation in Biotechnology Industry: Redefining What is 'Part of the Job' of Researchers in Industry. Sci. Eng. Ethics 2013, 19, 1141-1164. [CrossRef] [PubMed]

24. Long, T.B.; Blok, V. Integrating the management of socio-ethical factors into industry innovation: Towards a concept of Open Innovation 2.0. Int. Food Agribus. Manag. Rev. 2018, 21, 463-486. [CrossRef]

(C) 2019 by the authors. Licensee MDPI, Basel, Switzerland. This article is an open access article distributed under the terms and conditions of the Creative Commons Attribution (CC BY) license (http://creativecommons.org/licenses/by/4.0/). 